\title{
Optimization of WEDM process of mould material using Kriging model to improve technological performances
}

\author{
TRUNG-THANH NGUYEN ${ }^{1,2, * \mathbb{D}}$ and QUOC-DUNG DUONG ${ }^{2}$ \\ ${ }^{1}$ Institute of Research and Development, Duy Tan University, 03 Quang Trung, Da Nang 550000, Viet Nam \\ ${ }^{2}$ Faculty of Mechanical Engineering, Le Quy Don Technical University, 236 Hoang Quoc Viet, Ha Noi 100000, \\ Viet Nam \\ e-mail: trungthanhk21@mta.edu.vn
}

MS received 11 September 2018; revised 24 March 2019; accepted 4 April 2019; published online 30 May 2019

\begin{abstract}
Improving the technical performance of the wire electro-discharge machining (WEDM) process is an effective solution to decrease manufacturing costs. This paper addresses a multi-response optimization to simultaneously improve the cutting area rate $C A R$ and decrease the kerf width $A K W$, while the average surface roughness $A S R$ is predefined as a constraint. The processing conditions considered include the pulse-on time $T_{\text {on }}$, the current $I$, the voltage $V$ and the wire speed $S$. A WEDM machine was adopted in conjunction with the BoxBehnken matrix to conduct experimental trials for machining of SKD61 steel. Highly nonlinear relationships between machining parameters and technological outputs were developed using the Kriging models. Finally, an archive-based micro-genetic algorithm (AMGA) was used to resolve the trade-off analysis among three responses and determine the optimal values of the processing factors. The results showed that a set of feasible solutions can be determined for the low kerf width as well as the surface roughness and the high cutting area rate. The selection of optimum parameters could help the WEDM operators to save the machining costs and time. The combination of the Kriging model and AMGA could be considered as an intelligent approach for modelling WEDM processes and predicting optimal results.
\end{abstract}

Keywords. WEDM; mould material; cutting area rate; surface roughness; kerf width; Kriging model.

\section{Introduction}

The important task of machining processes is to improve technological performances, such as processing efficiency, the machined part quality and the accuracy. The first solution focuses on the improvement of the machine's components and technologies, such as smart control [1] and advanced devices [2]. The second method pays attention to optimization of processing conditions to ensure the technical targets. Apparently, the determination of optimal factors is inexpensive and has better sustainable development, as compared with dramatic investments. Consequently, improving the machining criteria by means of optimal conditions can be considered to be an intelligent choice.

The effects of processing conditions on the technical outputs of the wire electro-discharge machining (WEDM) processes have been investigated by many researchers. The parameters were optimized in an effort to improve the working performances for the WEDM processes of SKD11 steel [3], EN 353 steel [4] and AISI D3 [5] material. Additionally, investigators solved the trade-off among

*For correspondence multi-responses for the WEDM processes of YG15 steel [6], AISI D2material [7] and Inconel alloys [8, 9]. Recently, optimal processing conditions for the WEDM processes of composite materials were studied [10-12]. The technological responses considered were the cutting speed, the material removal rate $(M R R)$, the surface roughness properties, the kerf width and the wire wear ratio. Additionally, the depth of the recast layer, the crack density and the dimensional accuracy were also considered as important outputs. The factors optimized were the processing parameters (the pulse-on time, the pulse-off time, the spark current, the open voltage, the wire speed, the feed rate and the water pressure), the tool characteristics (the diameter, the material and the wire tension) and the workpiece properties.

As a result, different optimizing techniques, including the response surface methodology (RSM) [13-15], the Taguchi-based methods [16-18], the fuzzy neural system (FNS) [19-21] and the artificial intelligence (AI) [22-24], were used to explore the relationships between inputs and outputs. However, the aforementioned works regarding parametric optimization for the WEDM processes have still the following deficiencies. 
When the relationships between inputs and outputs are highly nonlinear, the traditional technique, such as RSM, does not ensure predictive accuracy due to an estimating error [25]. The other approaches, including AI and FNS, are considered to be better than the RSM models when modelling the nonlinear WEDM processes. Additionally, the Taguchi-based methods could be used for local optimization due to discrete space.

The investigators have selected the optimal conditions for minimizing surface roughness. Practically, the surface roughness is a technical requirement, which should be defined before the actual machining to save the machining time and costs.

Predictive models, which can be used to render the nonlinear relationships between the inputs and the outputs, including the cutting area rate $(C A R)$, surface roughness and kerf width for the WEDM process of the SKD61 material, have not been presented in the aforementioned works.

The optimum settings of machining factors may have inefficient results because of the strong conflicts among the technological performances.

To fulfill the mentioned research gaps, a multiple-response optimization of process parameters of the WEDM process of mould material has been considered in this paper for improving the technical performances. Furthermore, we recognized that the effects of processing conditions contributed to variations in measured performances, such as cutting efficiency, surface integrity and dimensional accuracy. Therefore, an effective approach for modelling WEDM process behaviour and the optimizing processing factors in terms of improving working performances is still a significant contribution.

In this work, the average surface roughness $(A S R)$, the average kerf width $(A K W)$ and the $C A R$ are considered as important responses. The Kriging model is used instead of RSM and Taguchi to render the highly nonlinear relationships between machining parameters and technical responses. The Kriging model can be considered to be an effective approach with regard to the highly nonlinear characteristic. An evolutionary archive-based micro-genetic algorithm (AMGA) is used to generate the feasible design points and identify the best optimal solution.

\section{Materials and methods}

The material SKD61 is chosen in this work due to the wide application in the moulding industry and machine tool. The chemical composition of SKD61 material is shown in table 1. The workpiece prepared has the dimensions of 230 $\mathrm{mm} \times 90 \mathrm{~mm} \times 8 \mathrm{~mm}$. Four process parameters, including the current $I$, the pulse-on time $T_{o n}$, the voltage $V$ and the wire speed $S$, as well as three levels $(-1,0$ and +1$)$ are shown in table 2 . The ranges of the parameters are chosen
Table 1. Chemical composition of SKD61.

\begin{tabular}{ccccccccc}
\hline $\mathrm{C}$ & $\mathrm{Si}$ & $\mathrm{Mn}$ & $\mathrm{P}$ & $\mathrm{S}$ & $\mathrm{Cr}$ & $\mathrm{Mo}$ & $\mathrm{Cu}$ & $\mathrm{V}$ \\
\hline 0.38 & 0.9 & 0.28 & 0.03 & 0.02 & 4.9 & 1.2 & 0.26 & 0.95 \\
\hline
\end{tabular}

Table 2. Process parameters and their levels.

\begin{tabular}{lcccc}
\hline Symbol & Parameters & Level -1 & Level 0 & Level +1 \\
\hline$I$ & Current (A) & 2 & 5 & 8 \\
$T_{\text {on }}$ & Pulse-on time $(\mu \mathrm{s})$ & 1 & 3 & 5 \\
$V$ & Voltage $(\mathrm{V})$ & 30 & 50 & 70 \\
$S$ & Wire speed $(\mathrm{m} / \mathrm{min})$ & 4 & 6 & 8 \\
\hline
\end{tabular}

based on the machine tool's characteristics, the recommendations of the wire's manufacturer and material properties. These values are then verified by machining trials in order to ensure machinability and avoid any interruptions.

\subsection{Optimization framework}

The systematic optimizing procedure is displayed in figure 1 in order to develop predictive models and determine optimal values. An experimental matrix generated by the Box-Behnken method is applied to save the experimental costs [26-28]. The predictive models of the $A K W$, the $A S R$ and the $C A R$ are then developed with respect to process parameters using the Kriging approach.

In this paper, the AMGA is applied to find a set of feasible solutions, which can be used to enhance the surface integrity. AMGA is an evolutionary technique, in which each objective is individually resolved. The mutation and solution are conducted using the chosen designs. The search history and solution selection are performed by means of a myriad of different heuristics. The optimal values of the parameters and responses are identified at the end of the convergent run. Therefore, AMGA can be used to find global optimization with low computational effort [29-31].

\subsection{Experiments and measurements}

A CNC WEDM machine, namely MTL-SFL70, is used to perform the experimental runs as depicted in figure $2 \mathrm{a}$. A molybdenum wire of diameter $0.18 \mathrm{~mm}$ is used as the tool material. A constant machining length of $35 \mathrm{~mm}$ in the workpiece is obtained in each experimental run. A new wire is used in order to eliminate possible interferences.

The ASR $(\mu \mathrm{m})$ is an important indicator of the surface integrity, which is measured in the horizontal and vertical 


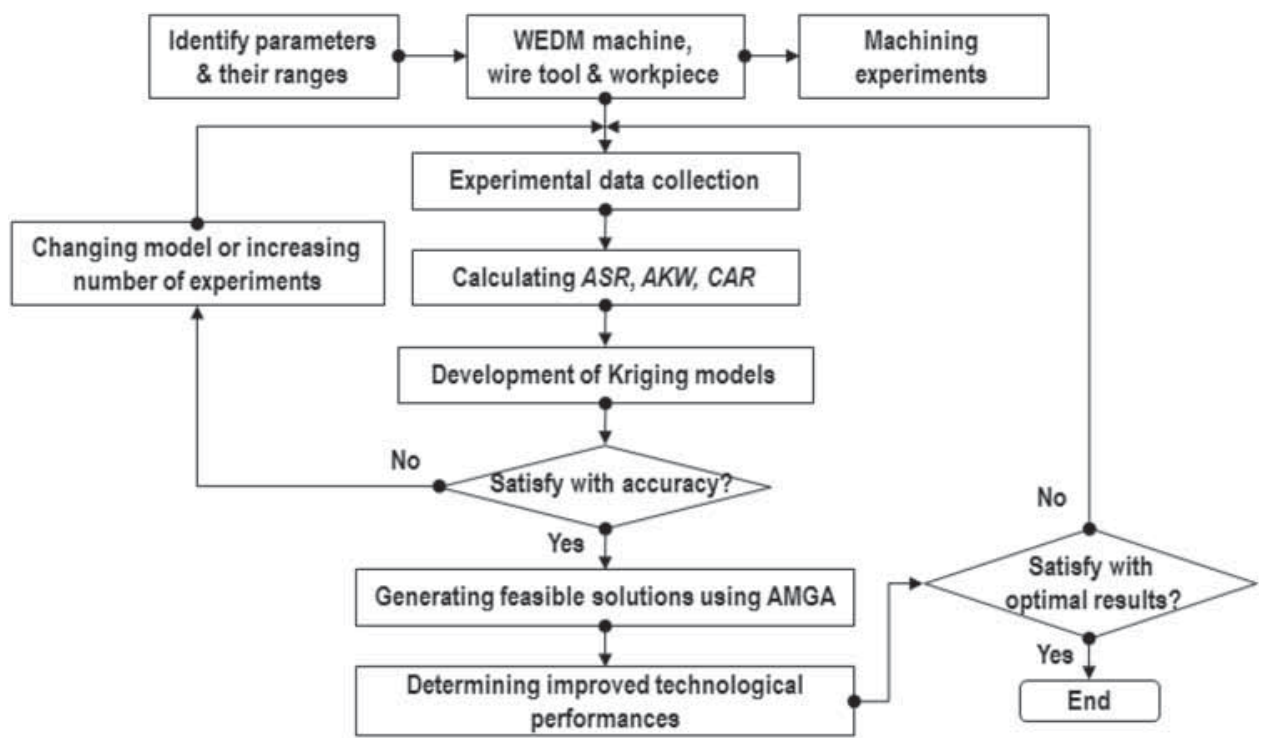

Figure 1. Systematic optimization procedure.

directions using a roughness tester Mitutoyo SJ-301, as shown in figure $2 \mathrm{~b}$. Values are obtained from five positions and the average is calculated using the following formula:

$$
\begin{gathered}
\operatorname{Rax}=\frac{\operatorname{Rax} 1+\operatorname{Rax} 2+\operatorname{Rax} 3+\operatorname{Rax} 4+\operatorname{Rax} 5}{5} \\
R a y=\frac{\operatorname{Ray} 1+\operatorname{Ray} 2+\operatorname{Ray} 3+\operatorname{Ray} 4+\operatorname{Ray5}}{5} \\
A S R=\frac{\operatorname{Rax}+\operatorname{Ray}}{2}
\end{gathered}
$$

where $R_{a x}(\mu \mathrm{m})$ and $R_{a y}(\mu \mathrm{m})$ denote the $A S R$ in $x$ - and $y$ direction, respectively.

The kerf width is an indicator of the wasted material, which is used to evaluate the dimensional accuracy of the machined part. Carl Zeiss 37081 Microscopy is used to measure the kerf width of all specimens, as shown in figure $2 \mathrm{c}$. The average value is calculated from the values at twenty positions over the entire length. The kerf width value is estimated using the following equation, as depicted in figure $2 \mathrm{~d}$ :

$$
A K W=\frac{1}{N} \sum_{i=1}^{N} K W_{i}
$$

where $K W_{i}$ and $N$ are the keft width at the $i$ position and the total number of measured points, respectively.

Generally, the $M R R$ is generally considered as a significant output variable. The $M R R\left(\mathrm{~mm}^{3} / \mathrm{min}\right)$ is calculated using the following equation:

$$
M R R=\frac{L * A K W * H}{t}
$$

where $L(\mathrm{~mm}), A K W(\mathrm{~mm}), H(\mathrm{~mm})$ and $t(\mathrm{~min})$ are the cutting length, the kerf width, the workpiece thickness and machining time, respectively. In this research, a cutting length of $35 \mathrm{~mm}$ is used for all machining runs. Therefore, we used a terminology, namely $C A R\left(\mathrm{~mm}^{2} / \mathrm{min}\right)$, which is defined as the ratio of the material removal in the machining area to the cutting time. The CAR can be considered as the criterion of production rate when the WEDM process is used to produce slots, grooves and open pockets in the workpieces, which have different thicknesses. The $C A R$ can be computed by the following equation:

$$
C A R=\frac{A K W \times H}{t}\left(\mathrm{~mm}^{2} / \mathrm{min}\right)
$$

\subsection{Kriging model}

The Kriging models of $A S R, A S K$ and $C A R$ in terms of processing factors are proposed using the experimental data. It can be described by means of Eq. (7):

$$
y(x)=p(x)+z(x)
$$

where $y(\mathrm{x})$ denotes the polynomial function to be developed, $p(x)$ is a known polynomial function and $z(x)$ is the realization of a normally distributed stochastic process [32].

The Kriging predictor at a specific value of $x$ is calculated as

$$
\widehat{y}(x)=\widehat{\beta}+r^{T}(x) R^{-1}(f-\widehat{p \beta})
$$

where $f$ denotes the column vector containing the sample data and $p$ is the filled column vector. The factor $\widehat{\beta}$ is calculated using the following equation:

$$
\widehat{\beta}=\left(p^{T} R^{-1} p\right)^{-1} p^{T} R^{-1} y
$$

In Eq. (8), $r^{T}(\mathrm{x})$ is the correlation vector and estimated as

$$
r^{T}(x)=\left[R\left(x, x^{1}\right), R\left(x, x^{2}\right), \ldots, R\left(x, x^{N}\right)\right]^{T}
$$




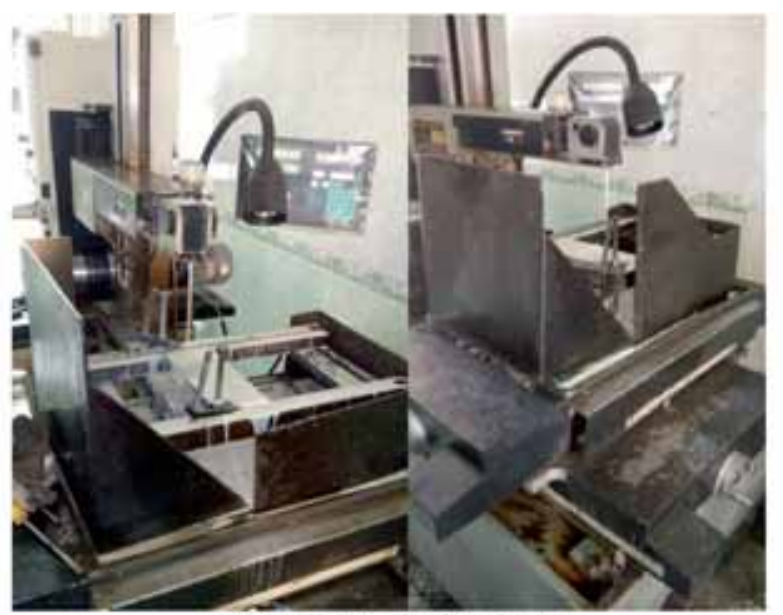

(a) WEDM experiments

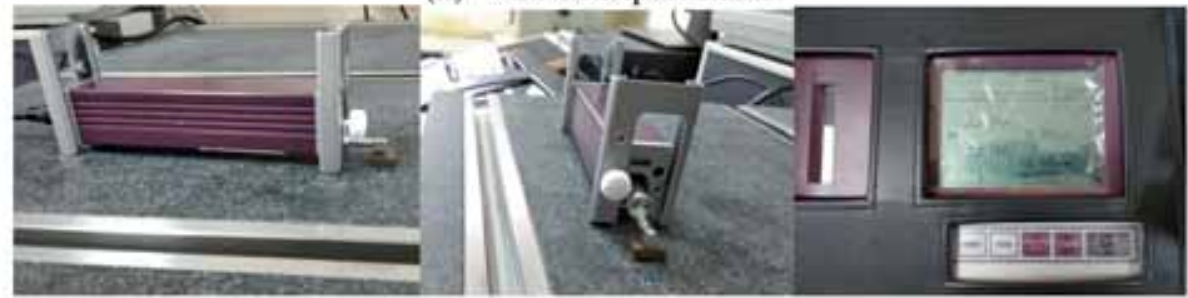

(b) Roughness measurement

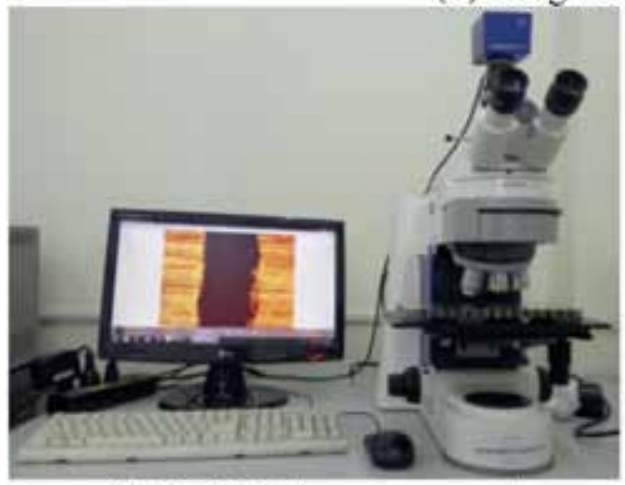

(c) Kerf width measurement

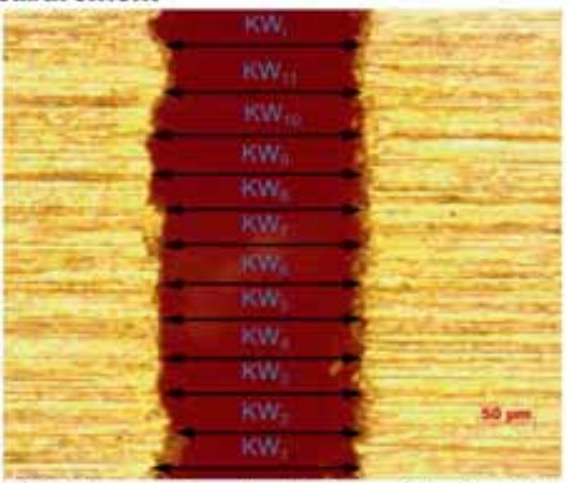

(d) Schematic calculation of kerf width

Figure 2. Experiments and measurements.

In this paper, the Gaussian correlative function is used and defined as

$$
R(\theta)=\exp \left[-\sum_{k=1}^{m} \theta_{k}\left(x_{k}^{i}-x_{k}^{j}\right)^{2}\right]
$$

The estimated variance of the proposed model is calculated as

$$
\widehat{\sigma}^{2}=\frac{(y-p \widehat{\beta}) R^{-1}(y-p \widehat{\beta})}{N}
$$

The correlation factor $\theta_{k}$ is estimated as

$$
\max \Phi\left(\theta_{k}\right)=-\frac{\left[N \ln \left(\widehat{\sigma}^{2}+\ln |R|\right]\right.}{2}
$$

where $\widehat{\sigma}^{2}$ and $|R|$ are functions of $\theta_{k}$.

\section{Results and discussion}

\subsection{Development of Kriging models}

The experimental results of the WEDM process are given in table 3 . The scalar factor $\beta$ and correlation parameter $\theta_{k}$ are obtained by means of the maximum likelihood method to develop the Kriging models, as shown in table 4. 
Table 3. Experimental results.

\begin{tabular}{|c|c|c|c|c|c|c|c|}
\hline No. & $\begin{array}{c}I \\
(\mathrm{~A})\end{array}$ & $\begin{array}{l}T_{\text {on }} \\
(\mu \mathrm{s})\end{array}$ & $\begin{array}{c}V \\
(\mathrm{~V})\end{array}$ & $\begin{array}{c}S \\
(\mathrm{~m} / \mathrm{min})\end{array}$ & $\begin{array}{l}A K W \\
(\mu \mathrm{m})\end{array}$ & $\begin{array}{l}A S R \\
(\mu \mathrm{m})\end{array}$ & $\begin{array}{c}C A R \\
\left(\mathrm{~mm}^{2} / \mathrm{min}\right)\end{array}$ \\
\hline \multicolumn{8}{|c|}{ Experimental data for developing Kriging models } \\
\hline 1 & 5 & 3 & 70 & 4 & 216.42 & 3.48 & 0.19056 \\
\hline 2 & 8 & 3 & 30 & 6 & 242.84 & 4.26 & 0.19015 \\
\hline 3 & 5 & 5 & 50 & 8 & 244.24 & 2.06 & 0.26184 \\
\hline 4 & 8 & 5 & 50 & 6 & 236.36 & 4.15 & 0.23414 \\
\hline 5 & 5 & 5 & 50 & 4 & 222.57 & 1.79 & 0.19870 \\
\hline 6 & 5 & 3 & 30 & 4 & 230.35 & 1.78 & 0.15839 \\
\hline 7 & 2 & 3 & 70 & 6 & 246.52 & 3.98 & 0.20933 \\
\hline 8 & 5 & 3 & 50 & 6 & 212.61 & 3.42 & 0.17297 \\
\hline 9 & 2 & 3 & 30 & 6 & 258.74 & 2.28 & 0.16629 \\
\hline 10 & 2 & 1 & 50 & 6 & 225.57 & 1.68 & 0.14751 \\
\hline 11 & 5 & 3 & 50 & 6 & 211.12 & 3.41 & 0.17234 \\
\hline 12 & 2 & 3 & 50 & 4 & 233.45 & 1.62 & 0.15350 \\
\hline 13 & 5 & 1 & 30 & 6 & 228.54 & 1.88 & 0.16563 \\
\hline 14 & 5 & 1 & 50 & 8 & 211.75 & 1.56 & 0.19173 \\
\hline 15 & 2 & 5 & 50 & 6 & 256.57 & 2.18 & 0.21784 \\
\hline 16 & 5 & 5 & 30 & 6 & 252.48 & 2.37 & 0.22306 \\
\hline 17 & 8 & 3 & 50 & 4 & 211.69 & 3.62 & 0.16826 \\
\hline 18 & 8 & 3 & 70 & 6 & 231.76 & 5.99 & 0.22500 \\
\hline 19 & 5 & 1 & 50 & 4 & 196.53 & 1.28 & 0.13672 \\
\hline 20 & 8 & 3 & 50 & 8 & 232.79 & 3.94 & 0.22659 \\
\hline 21 & 2 & 3 & 50 & 8 & 248.74 & 1.94 & 0.20076 \\
\hline 22 & 5 & 5 & 70 & 6 & 243.79 & 4.07 & 0.26736 \\
\hline 23 & 5 & 1 & 70 & 6 & 209.39 & 3.56 & 0.18697 \\
\hline 24 & 8 & 1 & 50 & 6 & 208.48 & 3.64 & 0.17063 \\
\hline 25 & 5 & 3 & 70 & 8 & 235.64 & 3.78 & 0.25159 \\
\hline 26 & 5 & 3 & 30 & 8 & 247.53 & 2.08 & 0.21452 \\
\hline \multicolumn{8}{|c|}{ Experimental data for testing accuracy } \\
\hline 27 & 2 & 3 & 50 & 4 & 234.54 & 1.63 & 0.15129 \\
\hline 28 & 5 & 5 & 50 & 6 & 232.78 & 2.87 & 0.22020 \\
\hline 29 & 8 & 1 & 70 & 8 & 231.35 & 4.06 & 0.24578 \\
\hline 30 & 2 & 3 & 70 & 4 & 240.28 & 2.82 & 0.19029 \\
\hline
\end{tabular}

\subsection{Model fitness}

The adequacy of the Kriging models can be assessed by the coefficients of determination, including $R^{2}, R^{2}$ adjusted and $R^{2}$ predicted. The $R^{2}$ coefficient is defined as the ratio of explained variation to the total variation and is a measure of the degree of fit. The adjusted $R^{2}$-value indicates the total variability that could be explained by the model after the significant factors were considered. The predicted $R^{2}$-value presents the total variability that could be expected by the model in any new data.

The $R^{2}$-values of $A S R, A K W$ and $C A R$ are $0.9894,0.9818$ and 0.9822 , respectively, indicating the good agreements between predicted and measured values. The adjusted $R^{2}$ values of $A S R, A K W$ and $C A R$ are $0.9834,0.9758$ and 0.9761 , respectively, proving the satisfactoriness of the models proposed. Additionally, the predicted $R^{2}$-values of ASR, AKW and CAR are 0.9714, 0.9678 and 0.9674, respectively, indicating the significances of the Kriging models in any new data (figure 3 ). Therefore, the adequacy of the Kriging models proposed for three responses is acceptable.

To exhibit the advantage of the proposed approach, comparisons of the values of $R^{2}, R^{2}$ adjusted and $R^{2}$ predicted for the Kriging and RSM models are performed. When the RSM models are used the $R^{2}$-values of $A S R$, $A K W$ and $C A R$ are $0.9543,0.9479$ and 0.9503 , respectively. The adjusted $R^{2}$-values for RSM models of $A S R, A K W$ and $C A R$ are 0.9494, 0.9424 and 0.9452 , respectively. Furthermore, the predicted $R^{2}$-values of $A S R, A K W$ and $C A R$ are $0.9384,0.9316$ and 0.9346 , respectively. Additionally, the data points generated by the Kriging models are more evenly distributed than the RSM ones (figure 4). This means that the adequacy of Kriging models is better than that of RSM methods. Similar outcomes can be found in the publications of $[25,33]$.

In this paper, Nos. 1-26 are used to develop Kriging models of machining responses and Nos. 27-30 are adopted for testing the accuracy of the obtained Kriging model. The comparisons between predicted values (PV) and experimental values $(\mathrm{EV})$ of the test points are shown in table 5. As a result, the percentage deviations for the $C A R, A S R$ and $A K W$ lie within the ranges of $-0.52 \%$ to $0.75 \%,-0.35 \%$ to $0.71 \%$ and $-1.03 \%$ to $0.93 \%$, respectively. The small errors indicate that the Kirging models are adequate and can be used for the optimizing process.

\subsection{The effects of processing conditions on the technical responses}

The effects of processing factors on the ASR are shown in figure $5 \mathrm{a}$. As a result, the surface roughness increased when the current changed from 2 to $8 \mathrm{~A}$ and voltage increased

Table 4. Values of Kriging model parameters.

\begin{tabular}{lccccc}
\hline & \multicolumn{4}{c}{ Correlation parameter $\theta_{k}$} & $V$ \\
\cline { 2 - 5 } Responses & $I$ & $S$ & $T_{\text {on }}$ & Scalar factor $\beta$ \\
\hline$A K W$ & 0.157514 & 0.093077 & 0.185455 & 0.229464 & 0.572705 \\
$A S R$ & 0.211879 & 0.148699 & 0.102242 & 0.163737 & -0.169793 \\
$C A R$ & 0.043371 & 0.181079 & 0.261909 & 0.208638 & 0.322109 \\
\hline
\end{tabular}




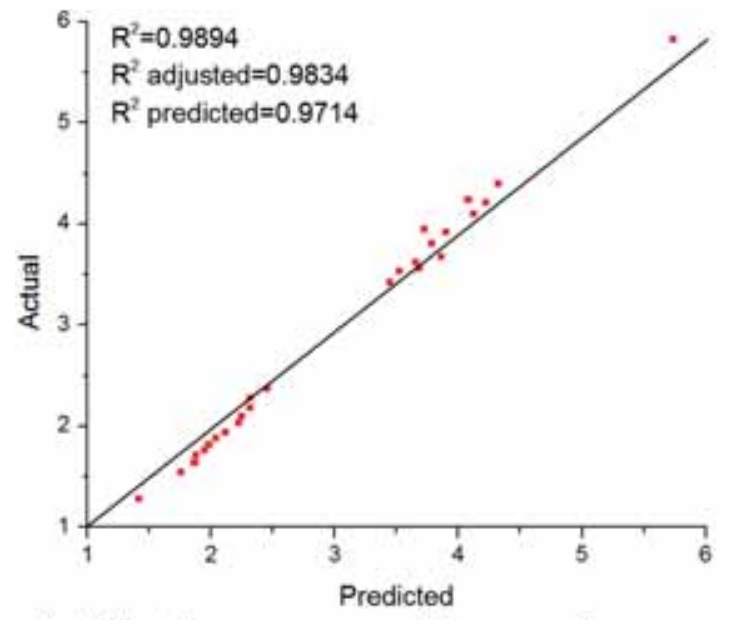

(a) For the average surface roughness

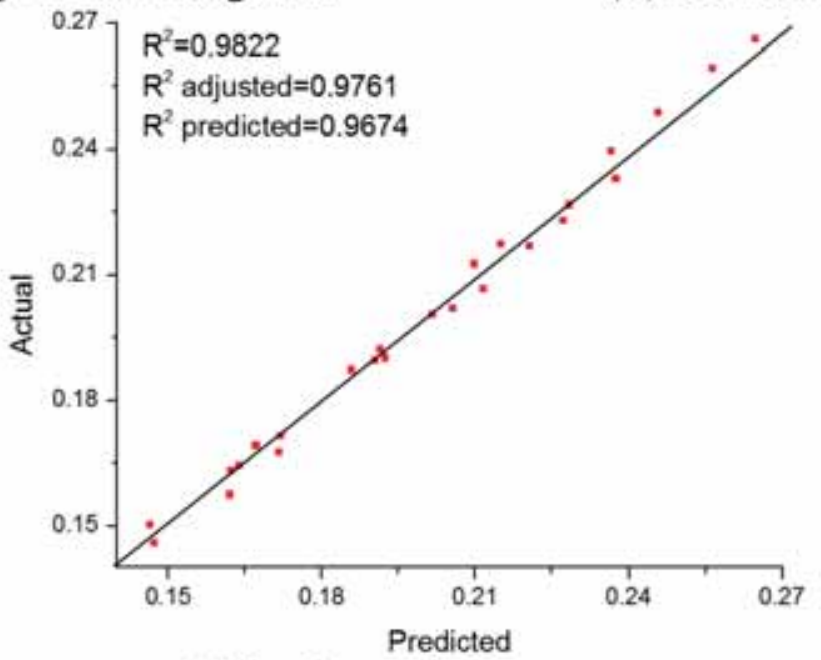

(c) For the cutting area rate

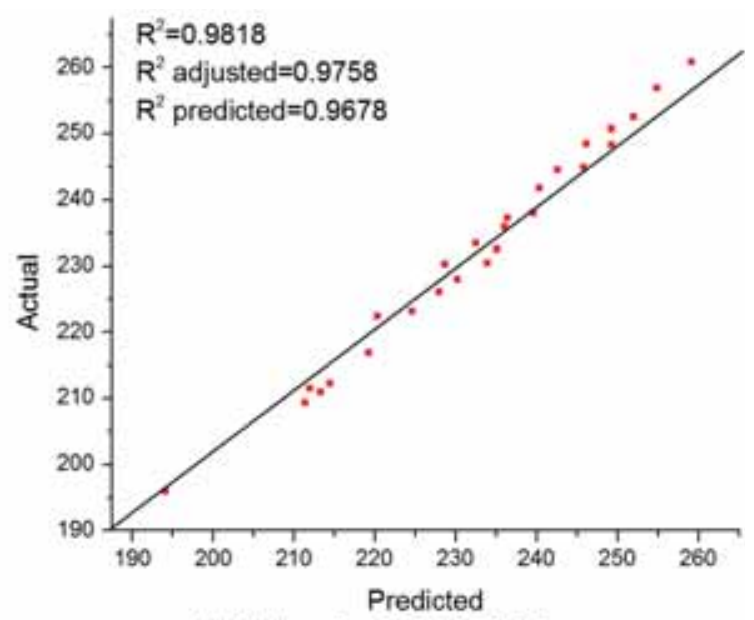

(b) For the kerf width

Figure 3. Investigations of the model accuracy for the Kriging models.

from 30 to $80 \mathrm{~V}$. At a low value of $I$ or $V$, the discharge energy will be low, leading to less material removal, which causes small craters and smooth surface. In contrast, the discharge energy will increase at a high value of $I$ or $V$, leading to excessive material removal, which results in larger and deeper craters.

Additionally, ASR is increased with an increment in the pulse-on time and then decreased by the continuously increased parameter. The longer the pulse-on time, the higher the discharge energy, which facilitates the melting and evaporation of materials; hence, the formation of bigger and deeper craters is observed. An increment in the pulse-on time results in excessive discharge energy, leading to even distribution of sparks. Obviously, smaller craters are produced.

Similarly, increased average roughness is associated with increased wire speed. After peak values, an increment of the wire speed leads to a smoother surface. The thermal energy is transferred to the wire and carried away from the work zone at a lower speed. Therefore, the low energy is used to melt the material, leading to smaller craters. An increased wire speed results in a faster washout and creates rapid occurrence of the EDM sparks. As a result, more thermal energy is used to melt and vaporize the materials, resulting in increased size craters [34]. An excessive increment in the wire speed leads to even distribution of the spark, which causes smaller sized craters and a smoother surface. Similar outcomes can be found in the work of [35].

As shown in figure $5 \mathrm{~b}$, an increase in the current or voltage causes higher discharge energy, which leads to an increment in the rate of melting and evaporation. The $C A R$ increases with increase in the pulse-on time because more material gets melted and evaporated, resulting in an improved $C A R$. A higher speed effectively influences the flushing of the debris material, contributing to a faster $C A R$. 


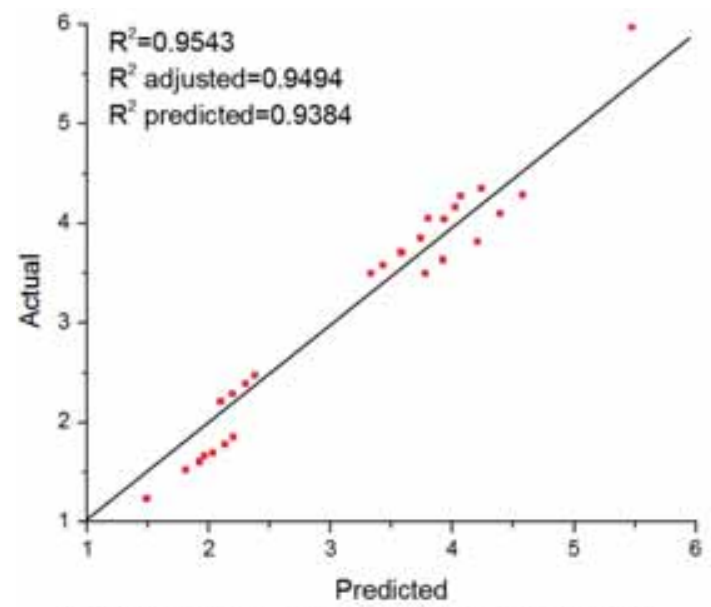

(a) For the average surface roughness

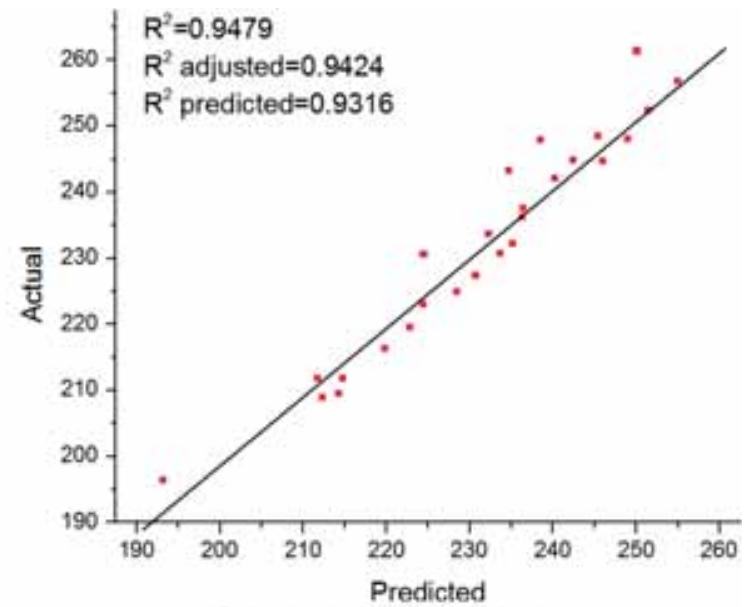

(b) For the kerf width

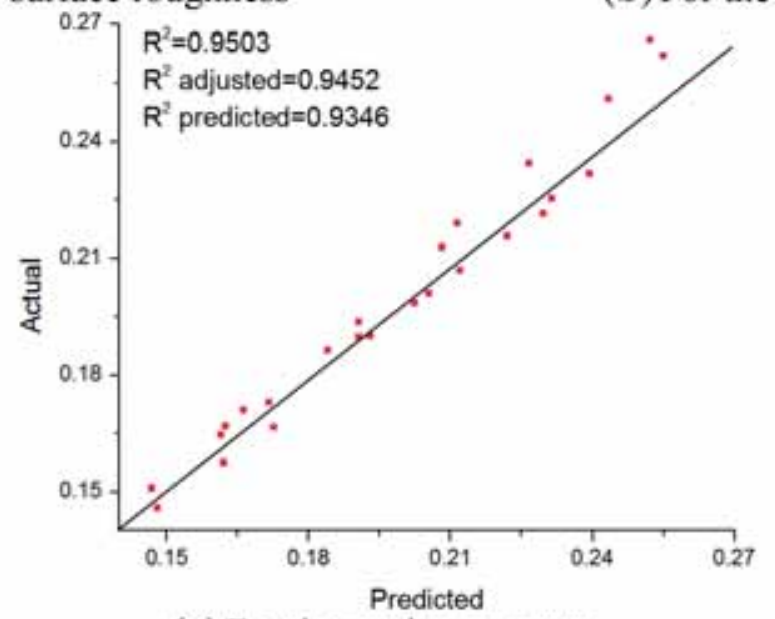

(c) For the cutting area rate

Figure 4. Investigations of the model accuracy for the RSM models.

Table 5. Comparison of predicted and experimental values.

\begin{tabular}{|c|c|c|c|c|c|c|c|c|c|}
\hline \multirow[b]{2}{*}{ No. } & \multicolumn{3}{|c|}{$A K W$} & \multicolumn{3}{|c|}{$A S R$} & \multicolumn{3}{|c|}{$C A R$} \\
\hline & $P V$ & $E V$ & Error $(\%)$ & $P V$ & $E V$ & Error $(\%)$ & $P V$ & $E V$ & Error $(\%)$ \\
\hline 27 & 232.37 & 234.54 & -0.93 & 1.64 & 1.63 & 0.61 & 0.15243 & 0.15129 & 0.75 \\
\hline 28 & 230.41 & 232.78 & -1.03 & 2.86 & 2.87 & -0.35 & 0.22168 & 0.22020 & 0.67 \\
\hline 29 & 230.62 & 231.35 & -0.32 & 4.08 & 4.06 & 0.49 & 0.24452 & 0.24578 & -0.52 \\
\hline 30 & 242.54 & 240.28 & 0.93 & 2.84 & 2.82 & 0.71 & 0.19146 & 0.19029 & 0.61 \\
\hline
\end{tabular}

Figure 5c shows that kerf width increases with longer pulse-on time. Higher discharge energy is available due to the increased duration, leading to an increase in the machining width. The increased kerf width is associated with increased wire speed. At a higher value of wire speed, faster washout is observed and the sparks occur rapidly. The higher discharge energy generated causes excessive material removal and resultantly leads to an increased kerf width. Furthermore, an excessive speed effectively influences on the flushing of the debris material, thereby increasing width [12, 34, 35].

An increase in current or voltage leads to a reduction of kerf width. After the shrinkage point, increased machining width is associated with increased current or voltage. At a higher value of $I$ or $V$, the debris may stick onto the workpiece surface, which leads to the erosion of the wire; hence, the diameter of the wire is decreased. Obviously, less kerf is produced [35]. An excessive increment in 

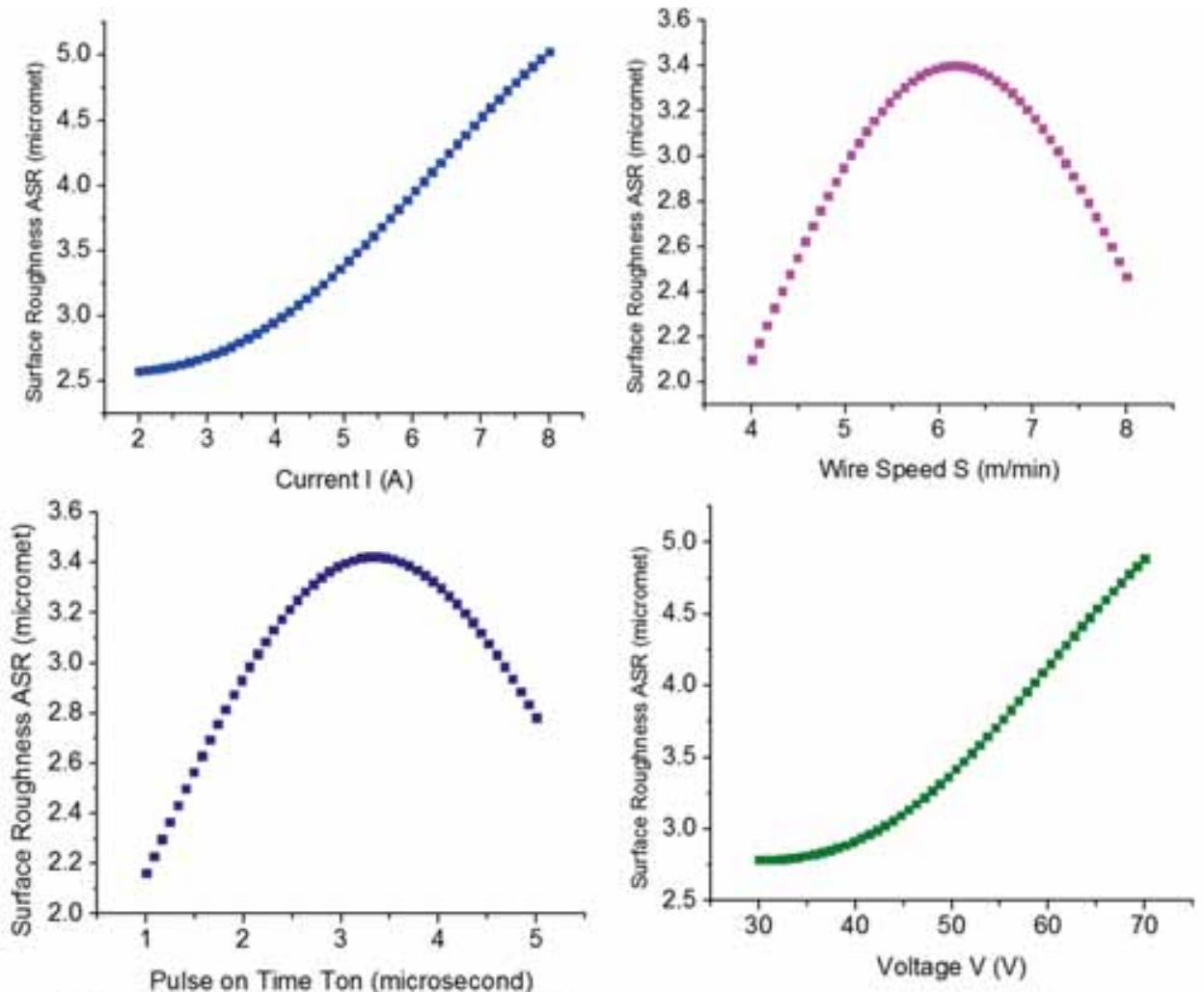

(a) Effects of processing conditions on the average surface roughness
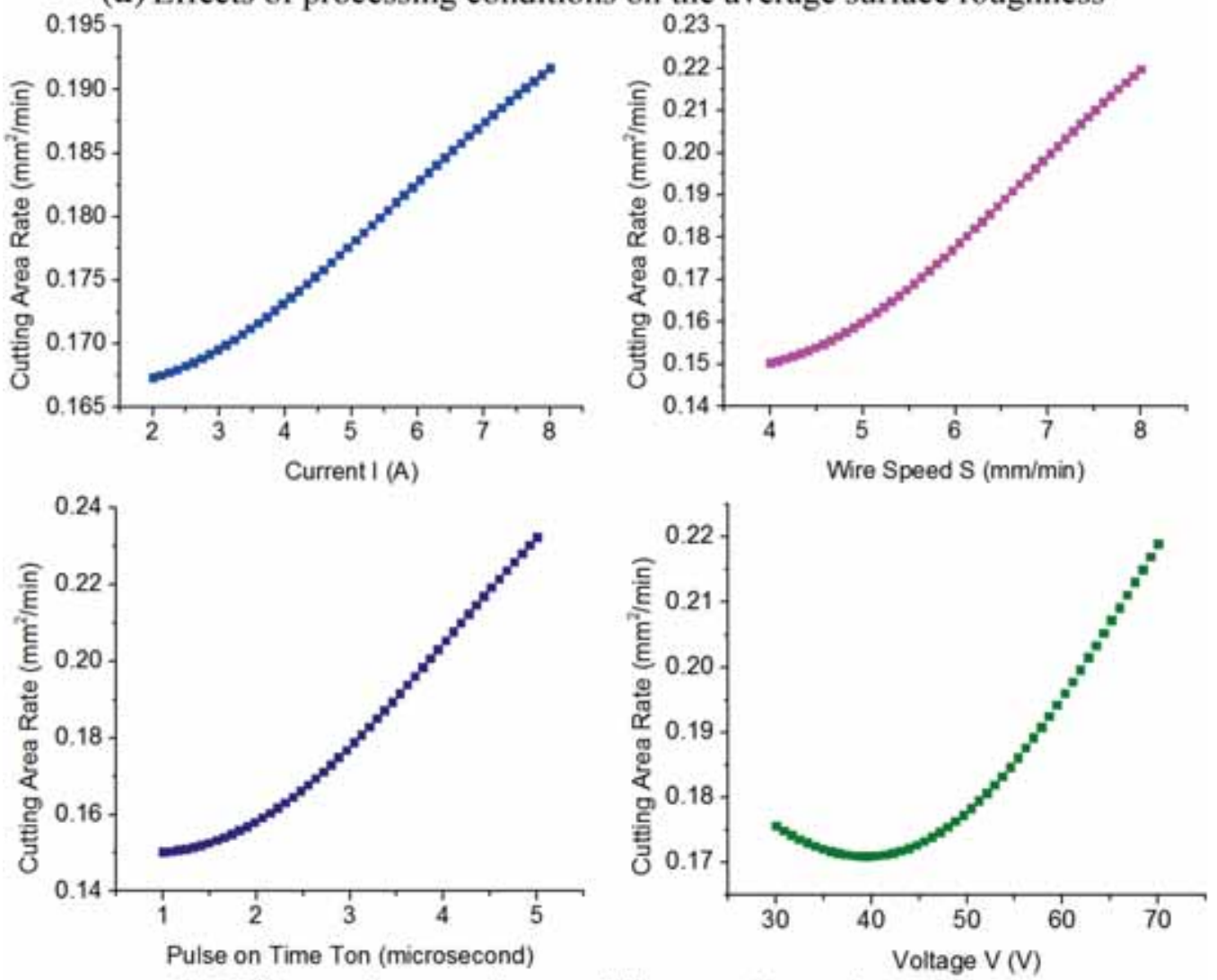

(b) Effects of processing conditions on the cutting area rate

Figure 5. Effects of process parameters on the WEDM responses. 

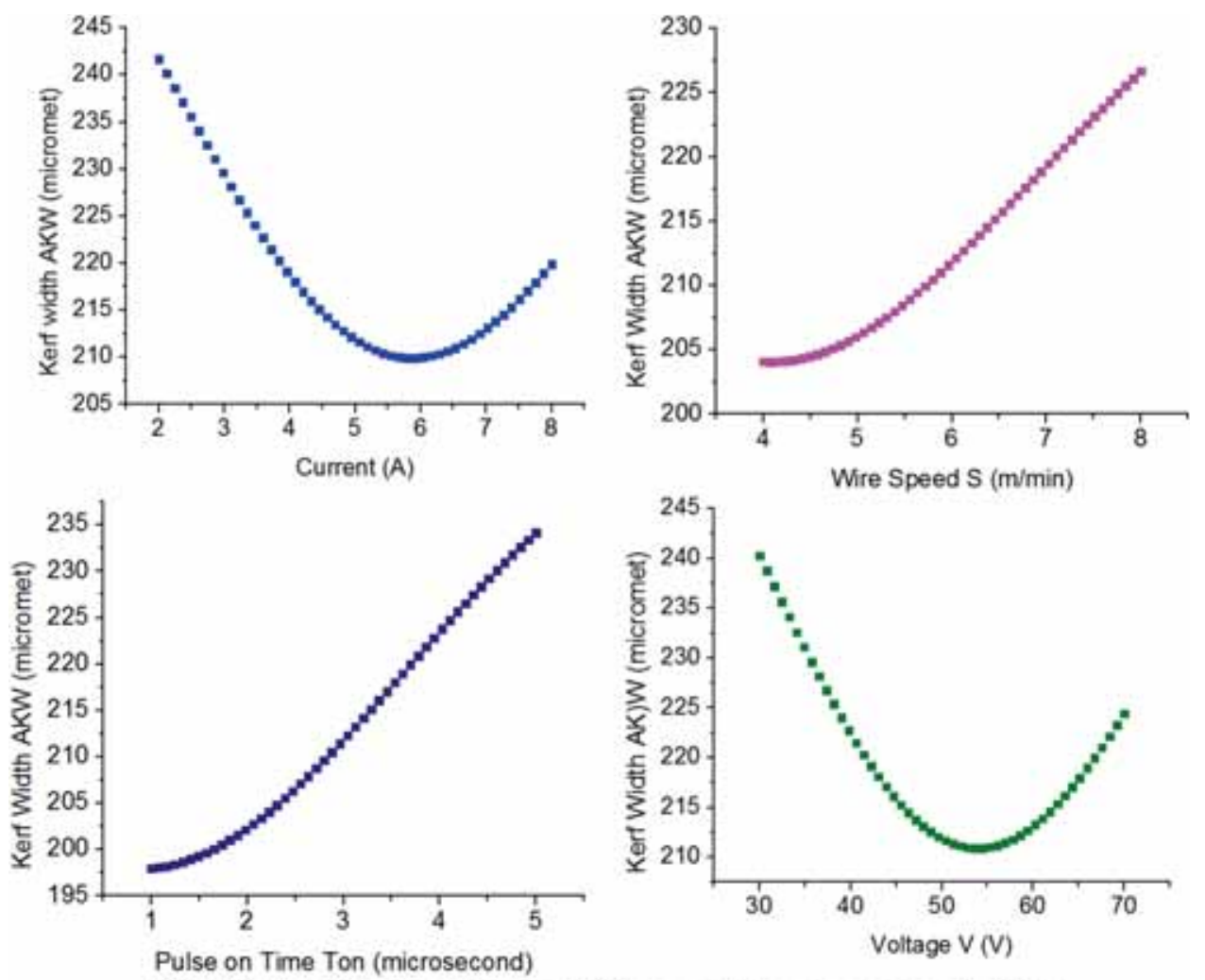

(c) Effects of processing conditions on the average kerf width

Figure 5. continued

current or voltage results in higher discharge energy, which leads to not only a higher MRR, but also effective flushing of the debris [34], thereby increasing groove. The crosssections of the kerf width at the different parameters are shown in figure 6.

A scanning electron microscope (SEM Nano Nova 450) is employed to explore the machined surface morphology at various machining conditions. The SEM images at different experimental conditions are shown in figure 7. A smoother surface having small cracks and holes is depicted at a low value of current, as shown in figure 7a. Bigger craters and cracks are found at a higher current (figure $7 b$ ). An increment in the wire speed could lead to an increase in surface roughness (figure $7 \mathrm{c}$ ), as compared with a low condition setting (figure $7 \mathrm{~d}$ ).

The combined effects of processing factors on the technical performances are depicted in figure 8 .

The contributions of inputs are depicted using Pareto charts, as shown in figure 9. The blue bar shows that the process parameters have a positive effect on the objective, while the red denotes a negative influence. In figure $7 \mathrm{a}$, all single terms, quadratic terms $\left(V^{2}\right.$ and $\left.I^{2}\right)$ and the interaction terms ( $I V$ and $T_{o n} V$ ) have a positive influence on the surface roughness. As a result, the percentage contributions of $I, V$, $T_{o n}$ and $S$ are $21.057 \%, 18.04 \%, 5.33 \%$ and $3.16 \%$, respectively. The $S^{2}$ accounts for the highest percentage contribution with respect to quadratic terms $(20.46 \%)$; this is followed by $T_{o n}^{2}(17.04 \%), V^{2}(7.58 \%)$ and $I^{2}(6.97 \%)$. The contributions of the interaction terms $I V$ and $T_{o n} V$ are $0.16 \%$ and $0.11 \%$, respectively, which have a positive effect on the surface roughness.

As shown in figure $7 \mathrm{~b}$, all quadratic terms, the single terms $\left(T_{o n}\right.$ and $\left.S\right)$ and two interaction terms $\left(T_{o n} V\right.$ and $T_{o n} S$ ) have a positive influence on kerf width. As a result, $V^{2}$ is the most affected factor due to the highest contribution $(19.98 \%)$ with regard to the quadratic term, followed by $I^{2}(18.47 \%), T_{o n}^{2}(4.49)$ and $S^{2}(3.83 \%)$. The pulse-ontime $T_{o n}$ has the largest positive effect on $A K W$ with a percentage of $16.85 \%$, followed by $S(10.52 \%), I(10.13 \%)$ and $V(7.38 \%)$. The contribution of interaction terms $T_{o n-}$ $V$ and $T_{o n} S$ are $3.00 \%$ and $1.86 \%$, respectively.

Figure $7 \mathrm{c}$ shows that all single terms and quadratic terms as well as the interaction terms $\left(T_{o n} V\right.$ and $\left.S I\right)$ have positive influences on the CAR. As a result, $V^{2}$ has the largest contribution with respect to quadratic terms $(13.79 \%)$, followed by $T_{o n}^{2}(10.06 \%), S^{2}(6.14 \%)$ and $I^{2}(2.69 \%)$. Especially, $T_{o n}$ is the most effective parameter due to the highest contribution regarding single terms $(21.52 \%)$, followed by $S(18.17 \%), V(11.34 \%)$ and $I(6.37 \%)$. The percentages of the interaction terms $T_{o n} V$ and $S I$ are $3.67 \%$ 


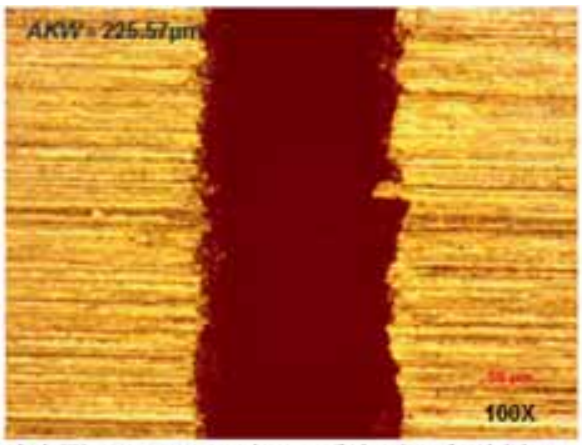

(a) The cross-sections of the kerf width at the $I=2(\mathrm{~A}), T_{\mathrm{om}}=1.0$ ( $\left.\mu \mathrm{s}\right), V=50.0(\mathrm{~V})$, and $S=6.0(\mathrm{~m} / \mathrm{min})$

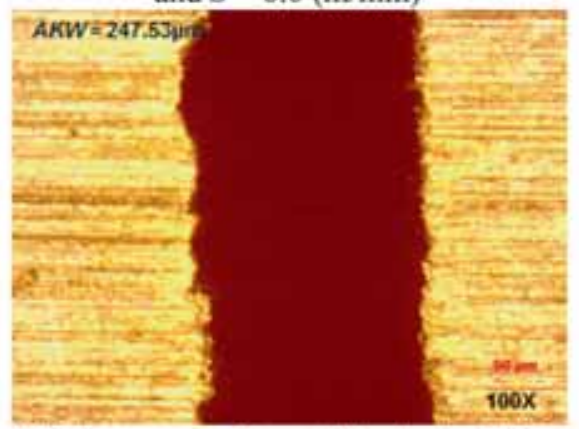

(c) The cross-sections of the kerf width at the $I=5(\mathrm{~A}), T_{\mathrm{om}}=3.0(\mu \mathrm{s}), V=30.0(\mathrm{~V})$, and $S=8.0(\mathrm{~m} / \mathrm{min})$

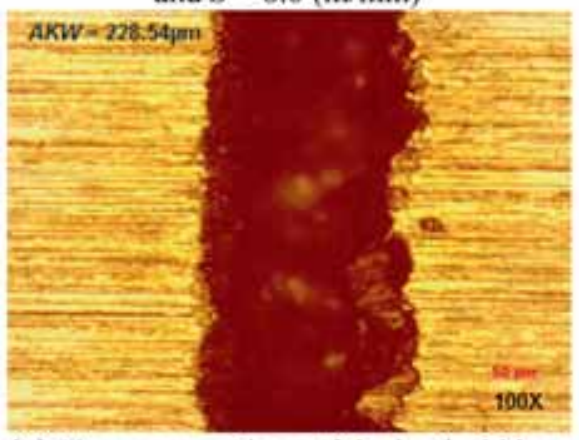

(e) The cross-sections of the kerf width at the $I=5(\mathrm{~A}), T_{\text {om }}=1.0$ ( $\left.\mu \mathrm{s}\right), V=30.0(\mathrm{~V})$, and $S=6.0(\mathrm{~m} / \mathrm{min})$

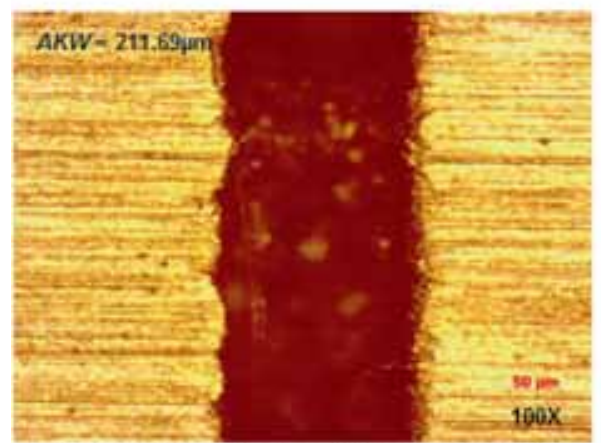

(g) The cross-sections of the kerf width at the $I=8(\mathrm{~A}), T_{o n}=3.0(\mu \mathrm{s}), V=50.0(\mathrm{~V})$. and $S=4.0(\mathrm{~m} / \mathrm{min})$

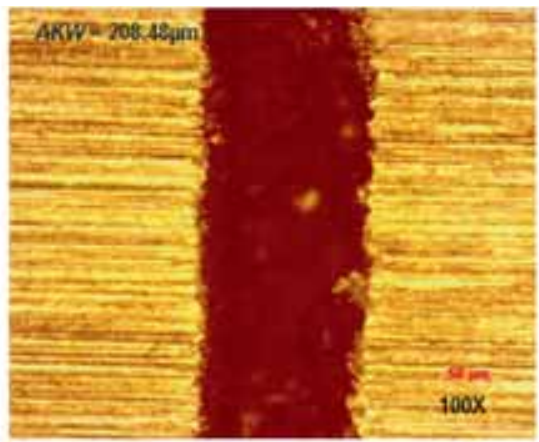

(b) The cross-sections of the kerf width at the $I=8(\mathrm{~A}), T_{\text {an }}=1.0(\mu \mathrm{s}), V=50.0$ (V), and $S=6.0(\mathrm{~m} / \mathrm{min})$

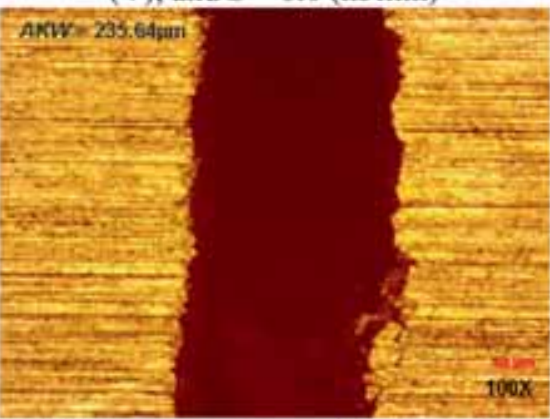

(d) The cross-sections of the kerf width at the $I=5(\mathrm{~A}), T_{\text {on }}=3.0(\mu \mathrm{s}), V=70.0$ (V), and $S=8.0(\mathrm{~m} / \mathrm{min})$

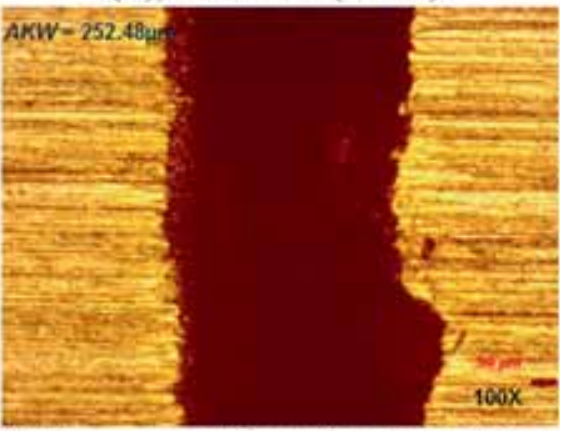

(f) The cross-sections of the kerf width at the $I=5(\mathrm{~A}), T_{o n}=5.0(\mu \mathrm{s}), V=30.0$ (V), and $S=6.0(\mathrm{~m} / \mathrm{min})$

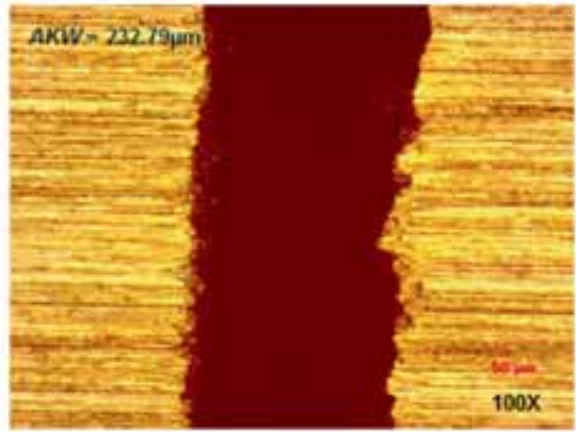

(h) The cross-sections of the kerf width at the $I=8(\mathrm{~A}), T_{\text {ox }}=3.0(\mu \mathrm{s}), V=50.0$ (V), and $S=8.0(\mathrm{~m} / \mathrm{min})$

Figure 6. The cross sections of the kerf width at various conditions. 


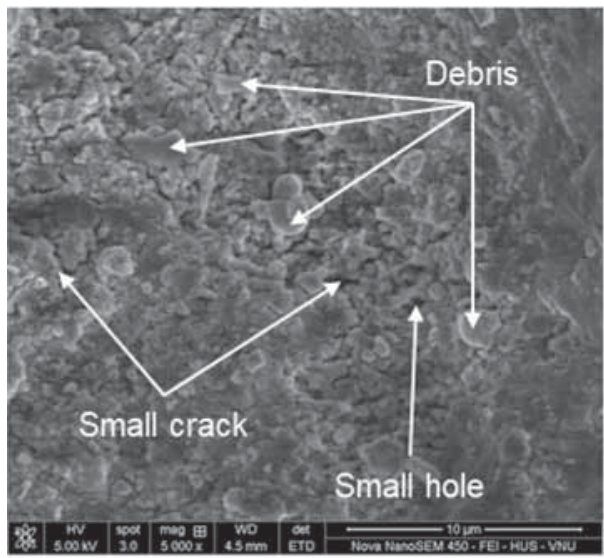

(a) SEM image at the $I=2(\mathrm{~A}), T_{\text {on }}=3.0$ $(\mu \mathrm{s}), V=50.0(\mathrm{~V})$, and $S=8.0(\mathrm{~m} / \mathrm{min})$

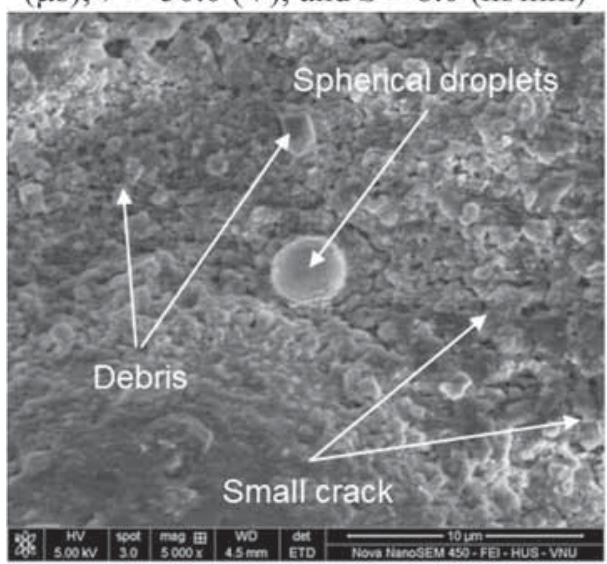

(c) SEM image at the $I=5(\mathrm{~A}), T_{\text {on }}=5.0$ ( $\mu \mathrm{s}), V=50.0(\mathrm{~V})$, and $S=8.0(\mathrm{~m} / \mathrm{min})$

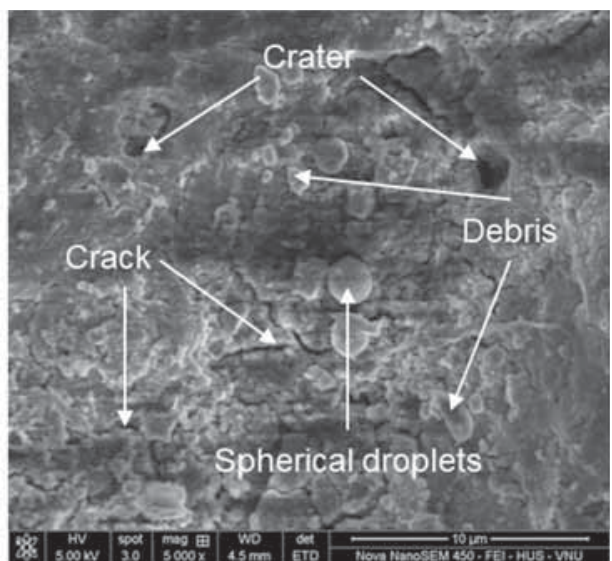

(b) SEM image at the $I=8(\mathrm{~A}), T_{\text {on }}=3.0$ ( $\mu \mathrm{s}), V=50.0(\mathrm{~V})$, and $S=8.0(\mathrm{~m} / \mathrm{min})$

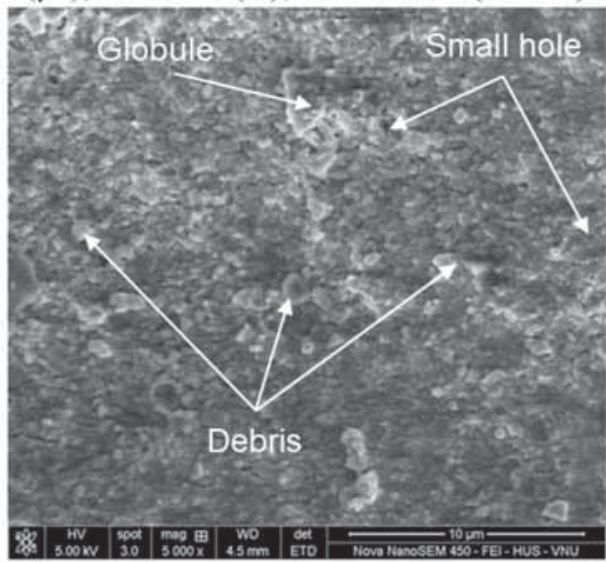

(d) SEM image at the $I=5(\mathrm{~A}), T_{\text {on }}=5.0$ ( $\mu \mathrm{s}), V=50.0(\mathrm{~V})$, and $S=4.0(\mathrm{~m} / \mathrm{min})$

Figure 7. Surface morphology at various conditions.

and $1.77 \%$, respectively. Other terms $\left(I T_{o n}, I V, T_{o n} S\right.$ and $V S)$ are listed as insignificant factors.

\section{Optimization results}

The developed mathematical models for the $C A R, A S R$ and $A K W$ are optimized using AMGA, which has the capacity of finding the optimal solution of a multi-objective problem. It is a tough work to determine the optimal process parameters for simultaneously improving three machining responses. Additionally, the processing factors, including current, voltage, pulse-on time and wire speed, have complex effects on the technical outputs. The optimizing issue can be described as follows:

find $X=\left[I, T_{o n}, V, S\right]$

maximize $C A R$; minimize $A K W$

constraints: $R_{a} \leq R_{\text {aupper }}$
$2 \leq I \leq 8(\mathrm{~A}), 1 \leq T_{\text {on }} \leq 5(\mu \mathrm{s}), 30 \leq V \leq 70(\mathrm{~V}), 4 \leq S \leq$ $8(\mathrm{~m} / \mathrm{min})$.

The developed equations showing the relationship between process parameters and machining responses are used to find optimal parameters by means of the AMGA. Single-objective optimizations for each objective are conducted to demonstrate the benefits of multi-objective optimization.

The optimizing results for maximizing the $C A R$ are exhibited in model I (table 6). Higher value of $C A R$ indicates an improved processing efficiency. Obviously, an absolute maximum for $C A R$ is observed when machining parameters are close to their highest values.

The results for minimizing kerf width are presented in model II. In this case, lesser kerf width indicates better response variable. As a result, the minimal kerf width is $196.42 \mu \mathrm{m}$ at a current of $5.86 \mathrm{~A}$, a voltage of $52.76 \mathrm{~V}$, a pulse-on time of $1.40 \mu \mathrm{s}$, and a wire speed of $4.50 \mathrm{~m} / \mathrm{min}$. 


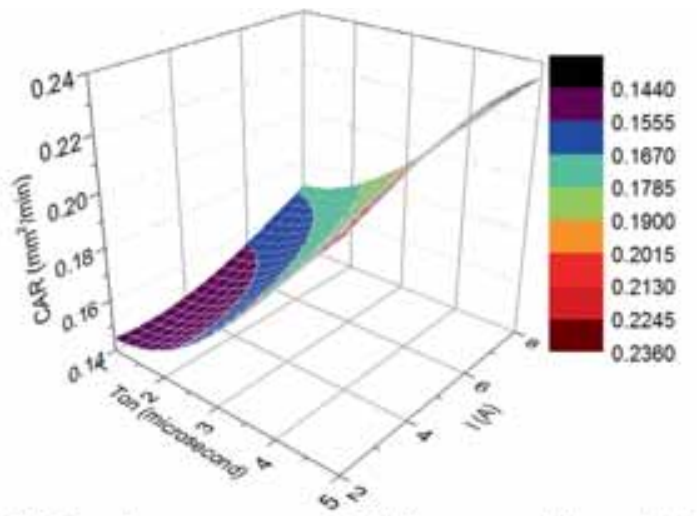

(a) Cutting area rate $C A R$ versus $T_{o n}$ and $I$

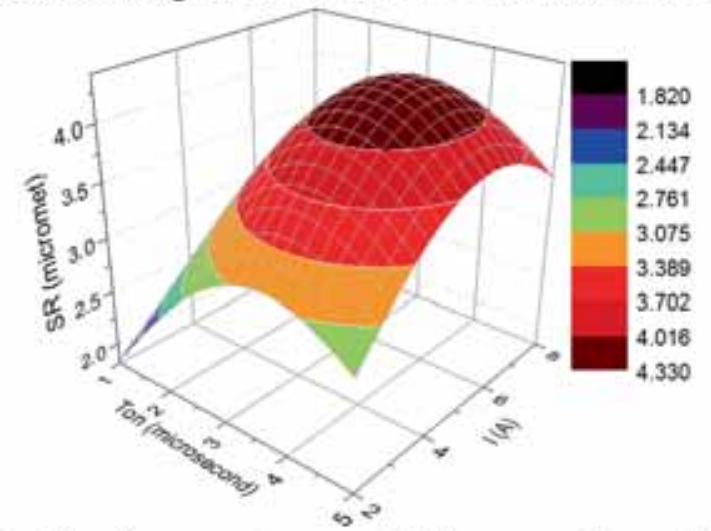

(c) Surface roughness $A S R$ versus $T_{o n}$ and $I$

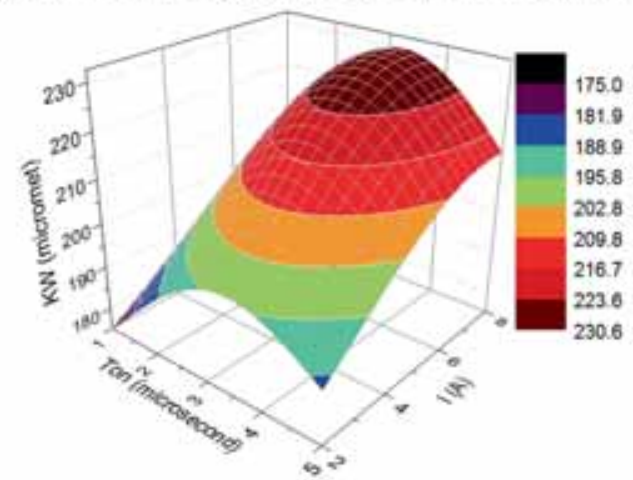

(e) Kerf width $A K W$ versus $T_{o n}$ and $I$

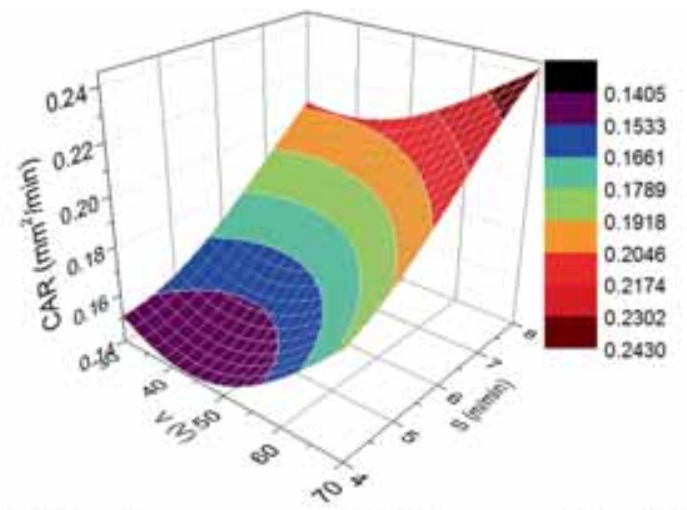

(b) Cutting area rate $C A R$ versus $V$ and $S$

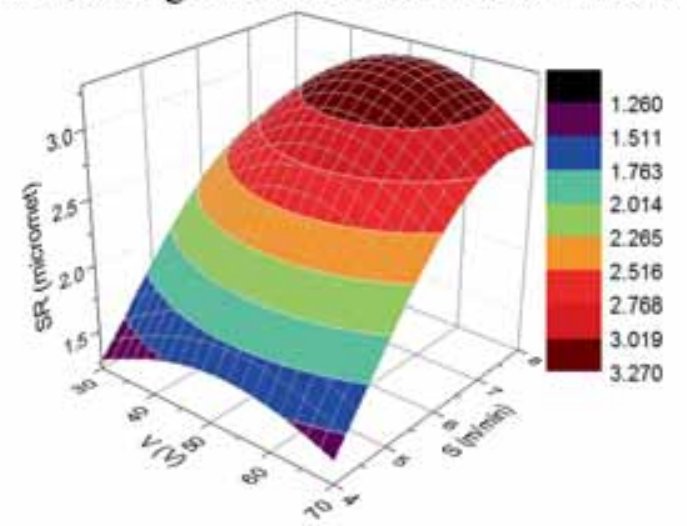

(d) Surface roughness $A S R$ versus $V$ and $S$

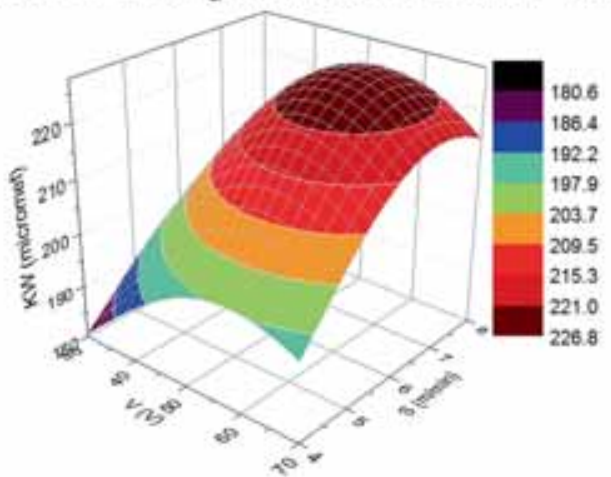

(f) Kerf width $A K W$ versus $V$ and $S$

Figure 8. Interaction effects of each machining parameter on the objectives.

Similarly, an improvement of surface roughness could be obtained by optimization. The optimal process parameters were found to be a current of $2.55 \mathrm{~A}$, a voltage of $42.00 \mathrm{~V}$, a pulse-on time of $1.95 \mu \mathrm{s}$ and a wire speed of $4.00 \mathrm{~m} / \mathrm{min}$ (model III).

The optimal parameters of the multi-objective optimization are selected from the Pareto front with the constrained surface roughness in the experimental range. The operating values of AMGA parameters population size, number of generations, crossover probability, crossover distribution index and mutation distribution index are 20, 40, 0.9, 10 and 20, respectively. The Pareto front generated by the AMGA algorithm is displayed in figure 10, in which the blue points are feasible solutions. As a result, the global relations among the technological responses shown in figure 10 can be used to determine the maximum values of 


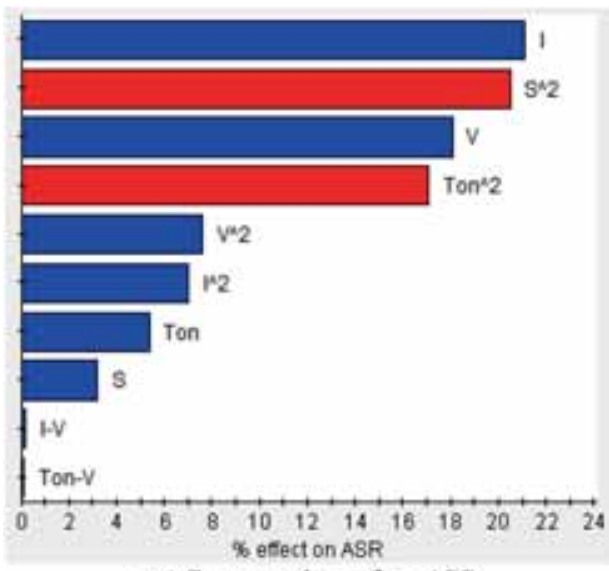

(a) Pareto chart for $A S R$

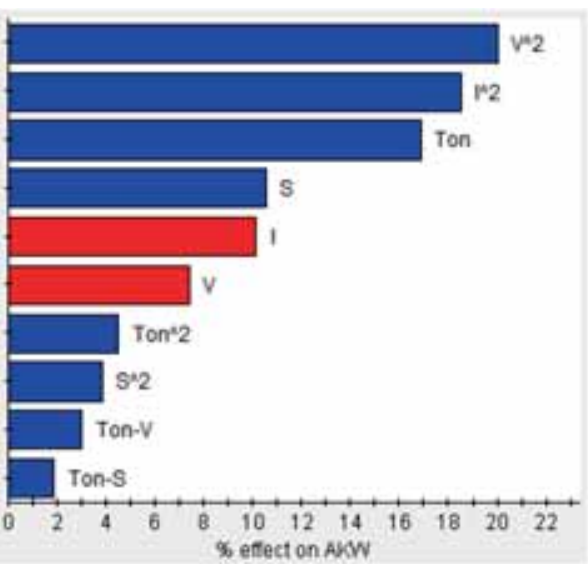

(b) Pareto chart for $A K W$

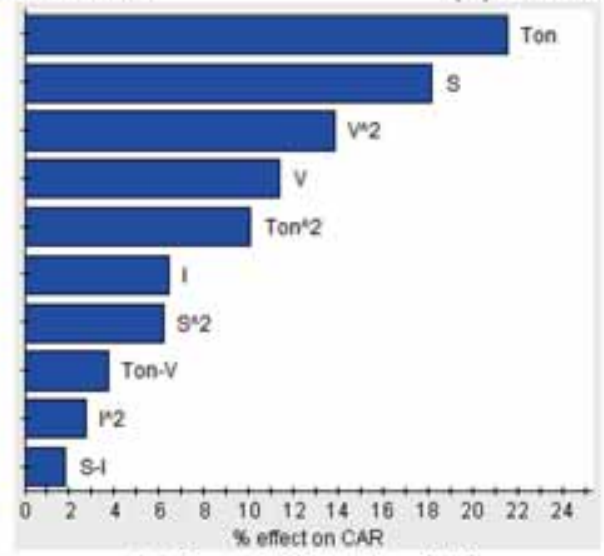

(c) Pareto chart for $C A R$

Figure 9. Pareto charts for three objectives.

Table 6. Optimization results.

\begin{tabular}{|c|c|c|c|c|c|c|c|}
\hline \multirow[b]{2}{*}{ Model } & \multicolumn{4}{|c|}{ Optimization parameters } & \multicolumn{3}{|c|}{ Responses } \\
\hline & $\begin{array}{c}I \\
\text { (A) }\end{array}$ & $\begin{array}{l}T_{\text {on }} \\
(\mu \mathrm{s})\end{array}$ & $\begin{array}{c}V \\
(\mathrm{~V})\end{array}$ & $\begin{array}{c}S \\
(\mathrm{~m} / \\
\min )\end{array}$ & $\begin{array}{r}C A R \\
\left(\mathrm{~mm}^{2} /\right. \\
\min )\end{array}$ & $\begin{array}{c}A K W \\
(\mu \mathrm{m})\end{array}$ & $\begin{array}{l}A S R \\
(\mu \mathrm{m})\end{array}$ \\
\hline I & 7.24 & 4.87 & 68.81 & 7.88 & 0.31 & & \\
\hline II & 5.86 & 1.40 & 52.76 & 4.50 & & 196.42 & \\
\hline III & 2.55 & 1.95 & 42.00 & 4.00 & & & 1.10 \\
\hline
\end{tabular}

$C A R$ and the minimal values of kerf width with the predefined constraints of ASR. The selection of the optimal point depends on the decision of the WEDM operators based on the weighting of $A K W$ and $C A R$ for a specific purpose. The representative scenarios with the constraints of ASR are shown in table 7.
Practically, when the operators use working experience or operating guide, it is hard to find the global optimum process parameters that maximize $C A R$ and minimize $A K W$ with a predefined $A S R$. Therefore, the contributions to the academy and industry of this research can be listed as the following:

The trade-off among ASR, kerf width and CAR is solved by means of optimization of machining factors for the WEDM process of the SKD61 material.

The Kriging models, which are employed here for depicting the nonlinear relationships between process parameters and machining responses, can be used to predict the output values with sufficient accuracy for the WEDM process of SKD 61 material. The Kriging method is more effective than the common approach (e.g., RSM) while dealing with the highly nonlinear relationships in the WEDM process. 


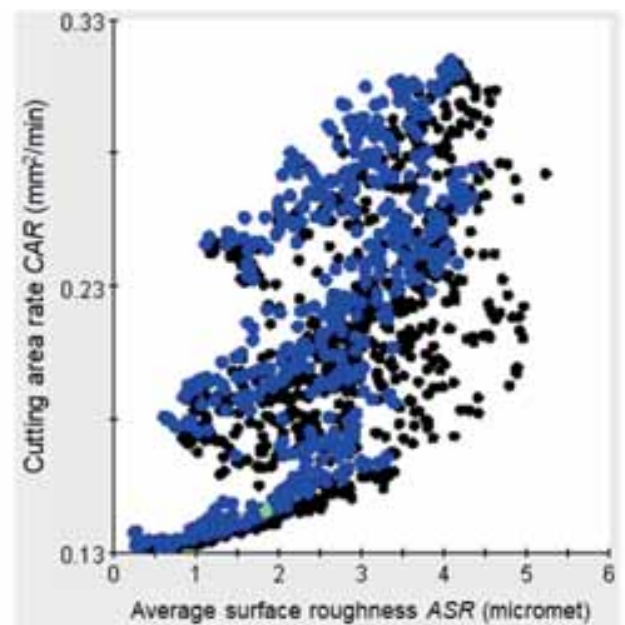

(a) Global relation between surface roughness and cutting area rate

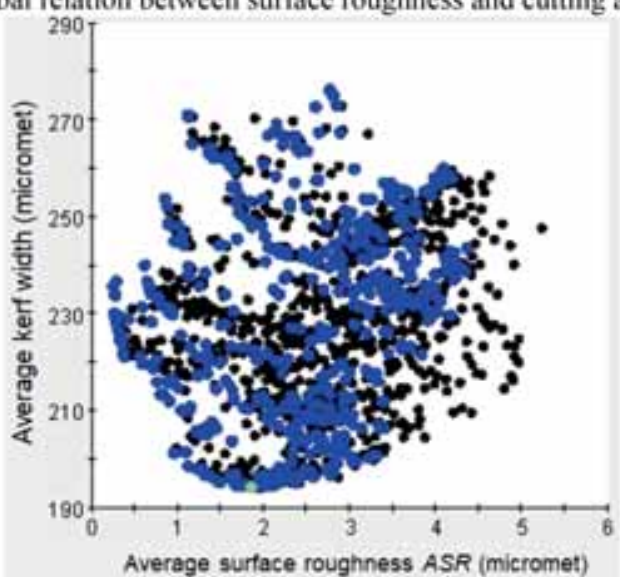

(b) Global relation between surface roughness and kerf width

Figure 10. Pareto fonts generated by AMGA.

When the ASR is predefined, the values of kerf width, $C A R$ and process parameters can be determined with the aid of the Pareto fronts. The selection of the proper solution depends on the desired targets in the specific machining case.

\section{Conclusions}

This paper presented an optimization based on machining parameters for the WEDM process of SKD61 material in order to maximize $C A R$, minimize kerf width and to keep the surface roughness below a desired limit. The Kriging models of three responses were developed in terms of processing factors, including the pulse-on time, the current, the voltage and the wire speed. An AMGA was used to predict the optimal values. The conclusions of this research can be listed as follows:

1. The Kriging models for $A S R$, kerf width and $C A R$ having $R^{2}$-values of $0.9894,0.9818$ and 0.9822 , respectively, indicate a good correlation between the predicted and experimental values. The models proposed effectively exhibited the nonlinear relationships in terms of processing parameters. The predictive models developed can be used for the WEDM process of SKD61 material to forecast the optimal parameters with sufficient accuracy.

2. The Pareto fronts generated by the AMGA can significantly support the WEDM operators to select appropriate parameters to decrease kerf width and increase $C A R$ with predefined constraints of the roughness criteria. The selection of optimal parameters can decrease the efforts required and machining costs as well as time.

3. The hybrid approach of the Kriging models and AMGA can be widely applied for the optimization of the WEDM process instead of using practical experience and operating guide. The method of approach in this research is multi-purposeful and can be used in all cases of WEDM processes with different materials.

4. This paper is expected to be a significant contribution to thoroughly investigate the effects of the process parameters on $A S R$, kerf width and CAR for the WEDM process of SKD61 material. It can be stated that the processing factors, including the pulse-on time, the current, the voltage and the wire speed, have significant impacts on the outputs. A higher value of surface

Table 7. Representative scenarios with constraints of the average surface roughness.

\begin{tabular}{|c|c|c|c|c|c|c|c|}
\hline \multirow[b]{2}{*}{ Scenario } & \multicolumn{4}{|c|}{ Optimization parameters } & \multirow{2}{*}{$\begin{array}{c}\text { Constraints } \\
\quad A S R \\
(\mu \mathrm{m})\end{array}$} & \multicolumn{2}{|c|}{ Responses } \\
\hline & $\begin{array}{c}I \\
(\mathrm{~A})\end{array}$ & $\begin{array}{l}T_{o n} \\
(\mu \mathrm{s})\end{array}$ & $\begin{array}{c}V \\
(\mathrm{~V})\end{array}$ & $\begin{array}{c}S \\
(\mathrm{~m} / \mathrm{min})\end{array}$ & & $\begin{array}{c}C A R \\
\left(\mathrm{~mm}^{2} / \mathrm{min}\right)\end{array}$ & $\begin{array}{l}A K W \\
(\mu \mathrm{m})\end{array}$ \\
\hline 1 & 3.71 & 1.02 & 41.28 & 7.15 & 1.50 & 0.16643 & 219.87 \\
\hline 1 & 3.23 & 5.00 & 55.74 & 7.83 & 2.00 & 0.26202 & 253.84 \\
\hline 3 & 5.36 & 1.02 & 51.89 & 6.92 & 2.50 & 0.17224 & 204.06 \\
\hline 4 & 6.03 & 5.00 & 65.08 & 4.06 & 3.00 & 0.23232 & 227.89 \\
\hline
\end{tabular}


roughness is observed with an increased pulse-on time or wire speed until it reaches the peak value and then with further factors, roughness continuously decreases. $A K W$ decreases with an increased current or voltage until it reaches the optimal point and then with further factors, roughness increases.

5. Solving the multi-objective optimization problem by considering surface roughness as a constraint is more practical and realistic in the WEDM processes, as compared with the models in which surface roughness is used as an optimization goal. The proposed approach combining Kriging models and AMGA could be used to solve the natural conflicts among milling performances and observe reliable parameter settings.

\section{References}

[1] Diaz N, Choi S, Helu M, Chen Y Y, Jayanathan S, Yasui Y, Kong D, Pavanaskar S and Dornfeld D 2010 Machine tool design and operation strategies for green manufacturing. In: Proceedings of the 4th CIRP International Conference on High Performance Cutting, Gifu, Japan

[2] Zhongde S, Shaoyan Q, Qian L and Feng L 2012 Key manufacturing technology \& equipment for energy saving and emissions reduction in mechanical equipment industry. Int. J. Precis. Eng. Manuf. 13: 1095-1100

[3] Zhang G, Zhang Z, Guo J, Ming W, Li M and Huang Y 2013 Modeling and optimization of medium-speed WEDM process parameters for machining SKD11. Mater. Manuf. Process. 28: 1124-1132

[4] Varun A and Venkaiah N 2015 Simultaneous optimization of WEDM responses using grey relational analysis coupled with genetic algorithm while machining EN 353. Int. J. Adv. Manuf. Technol. 76: 675-690

[5] Prasad D V S S S V and Gopala Krishna A 2015 Empirical modeling and optimization of kerf and wire wear ratio in wire electrical discharge machining. Int. J. Adv. Manuf. Technol. 77: 427-441

[6] Zhang Z, Ming W, Huang H, Chen Z, Xu Z, Huang Y and Zhang G 2015 Optimization of process parameters on surface integrity in wire electrical discharge machining of tungsten tool YG15. Int. J. Adv. Manuf. Technol. 81: 1303-1317

[7] Singh V, Bhandari B and Yadav V K 2017 An experimental investigation on machining parameters of AISI D2 steel using WEDM. Int. J. Adv. Manuf. Technol. 93: 203-214

[8] Shen Y, Liu Y, Dong H, Zhang K, Lin L, Zhang X, Wu X, Zheng C and Ji R 2017 Surface integrity of Inconel 718 in high-speed electrical discharge machining milling using air dielectric. Int. J. Adv. Manuf. Technol. 93: 691-698

[9] Mohanty A, Talla G and Gangopadhyay S 2014 Experimental investigation and analysis of EDM characteristics of Inconel 82. Mater. Manuf. Process. 29: 540-549

[10] Jangra K K 2015 An experimental study for multi-pass cutting operation in wire electrical discharge machining of WC5.3\% Co composite. Int. J. Adv. Manuf. Technol. 76: 971-982
[11] Dey A and Pandey K M 2018 Selection of optimal processing condition during WEDM of compocasted AA6061/cenosphere AMCs based on grey-based hybrid approach. Mater. Manuf. Process. 33: 1549-1558

[12] Lal S, Kumar S, Khan Z A and Siddiquee A N 2014 Multiresponse optimization of wire electrical discharge machining process parameters for A17075/A12O3/SiC hybrid composite using Taguchi-based grey relational analysis. Proc. Inst. Mech. Eng. Part B J. Eng. Manuf. 229: 229-237

[13] Sharma N, Khanna R, Gupta R D and Sharma R 2013 Modeling and multi-response optimization on WEDM for HSLA by RSM. Int. J. Adv. Manuf. Technol. 67: 2269-2281

[14] Garg M P, Kumar A and Sahu A K 2017 Mathematical modeling and analysis of WEDM machining parameters of nickel-based super alloy using response surface methodology. Sadhana 42: 981-1005

[15] Balasubramanian S and Ganapathy S 2011 Grey relational analysis to determine optimum process parameters for wire electro discharge machining (WEDM). Int. J. Eng. Sci. Technol. 3: 95-101

[16] Somashekar K P, Mathew J and Ramachandran N 2011 Multi-objective optimization of micro WEDM parameters using grey relational analysis with Taguchi method. Proc. Inst. Mech. Eng. C J. Mech. Eng. Sci. 225: 1-12

[17] Jangra K, Grover S and Aggarwal A 2012 Optimization of multi machining characteristics in WEDM of WC-5.3\% Co composite using integrated approach of Taguchi, GRA and entropy method. Front. Mech. Eng. 7: 288-299

[18] Muthu Kumar V, Suresh Babu A, Venkatasamy R and Raajenthiren M 2010 Optimization of the WEDM parameters on machining Incoloy800 super alloy with multiple quality characteristics. Int. J. Eng. Sci. Technol. 2: 1538-1547

[19] Bagherian Azhiri R, Teimouri R, Ghasemi Baboly M and Leseman Z 2014 Application of Taguchi, ANFIS and grey relational analysis for studying, modelling and optimization of wire EDM process while using gaseous media. Int. J. Adv. Manuf. Technol. 71: 279-295

[20] Lee W M and Liao Y S 2007 Adaptive control of the WEDM process using a self-tuning fuzzy logic algorithm with grey prediction. Int. J. Adv. Manuf. Technol. 34: 527-537

[21] Ahn C W 2017 A Multi-objective evolutionary approach to selecting security solutions. CAAI Trans. Intell. Technol. https://doi.org/10.1049/trit.2017.0002

[22] Yusoff Y, Zain A M, Amrin A, Sharif S, Haron H and Sallehuddin R 2017 Orthogonal based ANN and multi GA for optimization on WEDM of Ti-48Al intermetallic alloys. Artif. Intell. Rev. https://doi.org/10.1007/s10462-017-9602-2

[23] Yusoff Y, Zain A M, Amrin A, Sharif S, Sallehuddin R and Ngadiman M S 2018 Potential ANN prediction model for multiperformances WEDM on Inconel 718. Neural Comput. Appl. 30(7): 2113-2127

[24] Huang H 2017 Automated test data generation based on particle swarm optimization with convergence speed controller. CAAI Trans. Intell. Technol. https://doi.org/10.1049/ trit.2017.0004

[25] Keshtegara B, Mert C and Kisic Sakata O 2018 Comparison of four heuristic regression techniques in solar radiation modeling: Kriging method vs RSM, MARS and M5 model tree. Renew. Sust. Energ. Rev. 81: 330-341

[26] Pandya S and Menghani J 2018 Developments of mathematical models for prediction of tensile properties of 
dissimilar AA6061-T6 to $\mathrm{Cu}$ welds prepared by friction stir welding process using Zn interlayer. Sadhana 43:1-18

[27] Mohanty C P, Satpathy M P, Mahapatra S S and Singh M R 2018 Optimization of cryo-treated EDM variables using TOPSIS-based TLBO algorithm. Sadhana 43: 1-18

[28] Johnson J L 2018 Design of experiments and progressively sequenced regression are combined to achieve minimum data sample size. Int. J. Hydromechatron. 1: 308-311

[29] Liu G P, Han X and Jiang C 2012 An efficient multi-objective optimization approach based on the micro genetic algorithm and its application. Int. J. Mech. Mater. Des. 8: $37-49$

[30] Santosh T, Patrick K, Georges F and Kalyanmoy D 2008 AMGA: an archive based micro genetic algorithm for multi-objective optimization. In: Proceedings of the Genetic and Evolutionary Computation conference, Georgia, USA
[31] Panwar P and Michael P 2018 Empirical modelling of hydraulic pumps and motors based upon the Latin hypercube sampling method. Int. J. Hydromechatron. 1: 272-292

[32] Sakata S, Ashida F and Zako M 2008 Structural optimization using Kriging approximation. Comput. Methods Appl. Mech. Eng. 192: 923-939

[33] Kim B S, Lee Y B and Choi D H 2009 Comparison study on the accuracy of meta-modeling technique for non-convex functions. J. Mech. Sci. Technol. 23: 1175-1181

[34] Junaid A A, Mirza J, Muhammad A, Salman H, Ahmad W and Musharaf A 2017 Effects of wire-cut EDM process parameters on surface roughness of HSLA steel. Int. J. Adv. Manuf. Technol. 91: 1867-1878

[35] Rajmohan K and Senthil Kumar A 2017 Experimental investigation and prediction of optimum process parameters of micro-wire-cut EDM of 2205 DSS. Int. J. Adv. Manuf. Technol. 93: 187-201 